\title{
Findings at necropsy in the heart of a patient with anticardiolipin syndrome
}

\author{
JEREMY J MURPHY, * IAIN H LEACH $\dagger$ \\ From the Departments of ${ }^{\star}$ Medicine and $\dagger$ Pathology, University Hospital, Nottingham
}

SUMMARY A 40 year old man with a history of myocardial infarction and hypertension presented with transient cerebral ischaemic attacks, aortic regurgitation, a raised erythrocyte sedimentation rate, and thrombocytopenia. The anticardiolipin syndrome was diagnosed and he was treated with prednisolone and warfarin. He died two years later after the development of acute heart failure. At necropsy his heart showed widespread arteriolar thrombosis without vasculitis, recanalised large vessel occlusion, and a "post-inflammatory" valvulitis of the aortic valve.

The term anticardiolipin syndrome is a recent introduction but the disease itself is by no means new. False positive results on serological testing for syphilis were reported in a few patients with systemic lupus erythematosus long before lupus erythematosus cells and other immunological features were detected. ${ }^{1}$ These patients and those with the "lupus anticoagulant" were only recently recognised as forming a clinically distinct group that was liable to thrombosis, thrombocytopenia, and recurrent abortion. Although they are often negative for antinuclear factor, ${ }^{2}$ they have high titres of antibodies to phospholipids, which for convenience are measured as cardiolipin antibodies. These phospholipid antibodies may play a part in the thrombotic complications ${ }^{3}$ but they also interfere with in vitro coagulation tests, hence the confusing term "lupus anticoagulant". Systemic lupus erythematosus and the anticardiolipin syndrome are now regarded as separate but overlapping parts of the autoimmune spectrum.

Recent reports indicate that phospholipid antibodies are common both in young survivors of myocardial infarction ${ }^{4}$ and after coronary artery bypass grafting': furthermore, their presence is associated with recurrent thrombotic episodes. Cardiolipin antibodies and the clinical syndrome will be recognised with increasing frequency by cardiologists. In this report we highlight two further cardiac manifestations of the syndrome-aortic valve disease and left ventricular failure caused by small vessel thrombosis.

Requests for reprints to Dr Jeremy J Murphy, Department of Medicine, University Hospital, Nottingham NG7 2UH.

\section{Case report}

A 33 year old man first presented in 1978 with an anterior myocardial infarct. Hypertension and impaired renal function (urea $9.6 \mathrm{mmol} / \mathrm{l}$, creatinine $0.16 \mathrm{mmol} / \mathrm{l}$ ) were diagnosed five years later. He had an erythrocyte sedimentation rate of $15 \mathrm{~mm} / \mathrm{h}$, proteinuria of $0.3 \mathrm{~g} /$ day, and a normal intravenous urogram. He was treated with metoprolol and bendrofluazide.

When he was 40 temporal lobe epilepsy developed and a computed tomographic brain scan showed a right parietal infarct. Two months later he was admitted after two transient cerebral ischaemic attacks affecting the right arm. Livedo reticularis was present on his trunk, arms, and legs and aortic regurgitation was noted for the first time. The blood pressure was $140 / 70 \mathrm{~mm} \mathrm{Hg}$ and no other abnormal signs were present. He had a normochromic, normocytic anaemia of $102 \mathrm{~g} / \mathrm{l}$, a normal white count, and moderate thrombocytopenia $\left(118 \times 10^{9} / 1\right)$. The erythrocyte sedimentation rate was $100 \mathrm{~mm} / \mathrm{h}$.

Infective endocarditis was suspected but blood cultures were sterile. Further investigations showed a normal $\mathrm{C}$ reactive protein, $\mathrm{C} 3$, and $\mathrm{C} 4$ but very high concentrations of $\mathrm{C} 3$ degradation products (C3d). Neither antinuclear factor nor DNA antibodies were detected. The activated partial thromboplastin time was prolonged at 59 seconds (normal upper limit $48 \mathrm{~s}$ ) because a "lupus anticoagulant" was present. Serological testing for syphilis was negative. Cardiolipin antibodies of both IgM and IgG classes were measured by a solid phase enzyme linked immunosorbent assay (ELISA). ${ }^{6}$ The result was $>6 \mathrm{SD}$ above control samples, and after standardisation of the assay ${ }^{7}$ the IgG antibody concentration ranged from 150 to 250 units (normal upper limit 6 units). 
Cross sectional echocardiography showed thickening of the non-coronary cusp of the aortic valve. A biopsy specimen of skin and muscle taken from an area of livedo reticularis showed evidence of venous thrombosis in the subcutis but immunofluorescence was non-specific. A renal biopsy specimen showed only ischaemic changes without evidence of vasculitis or glomerulonephritis.

He was treated with warfarin and prednisolone (30 mg/day) and his haemoglobin and erythrocyte sedimentation rate returned to normal although concentrations of cardiolipin antibody and C3d remained high. Over the next two years he remained well with no change in the clinical signs or cardiothoracic ratio on chest $x$ ray, despite a reduction in the dose of prednisolone to $7.5 \mathrm{mg} /$ day. He died suddenly at home after a week of increasing breathlessness and fatigue.

At necropsy the heart was enlarged $(580 \mathrm{~g})$. The tricuspid, pulmonary, and mitral valves were normal. The aortic valve (fig 1) had thickened and fibrotic cusps with commissural fusion between the left and non-coronary cusps. There was a small fibrous nodule in the middle of the free margin of the non- coronary cusp, with cusp retraction resulting in functional aortic incompetence. The left ventricle $C$. was dilated and hypertrophied $(280 \mathrm{~g})$. There was an area of fibrosis in the anterior wall consistent with a previous infarct. Coronary angiography after death showed extensive recanalisation of the left anterior descending artery and a low grade stenosis on the posterior right coronary artery.

Histologically the aortic cusps were thickened and के fibrosed. The nodule on the non-coronary cusp was $\vec{\circ}$ composed of dense fibrous tissue with organising platelet thrombus at the free margin. The features $\vec{\omega}$ were those of a non-specific "post-inflammatory" valvulitis. The left anterior descending artery showed extensive recanalisation at the site of a small $\mathrm{N}$ underlying fibrous plaque. Stenosis of the right $\overrightarrow{-}$ coronary artery was caused by a small fibrous plaque $\triangle$ with overlying platelet thrombus: there was no 은 evidence of plaque fissuring in any of the levels examined.

The most striking finding was the presence of multiple platelet thombi within small intramyocar- $\vec{\varphi}$ dial arterioles (fig 2); these were present within the 0 territories of all three coronary arteries. Some were

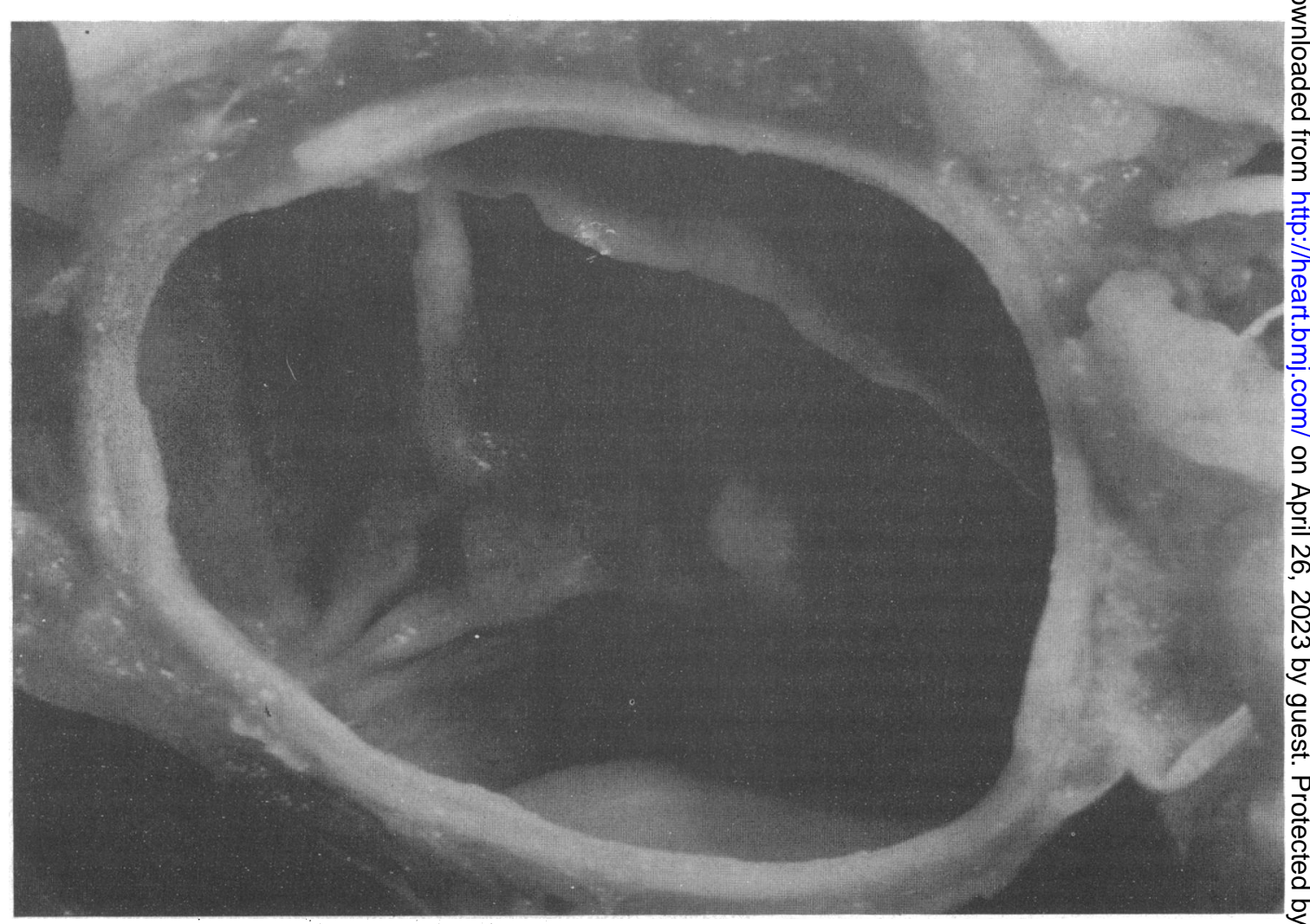

Fig 1 Aortic valve, viewed from the ascending aorta, showing cusp fusion and nodule formation. 


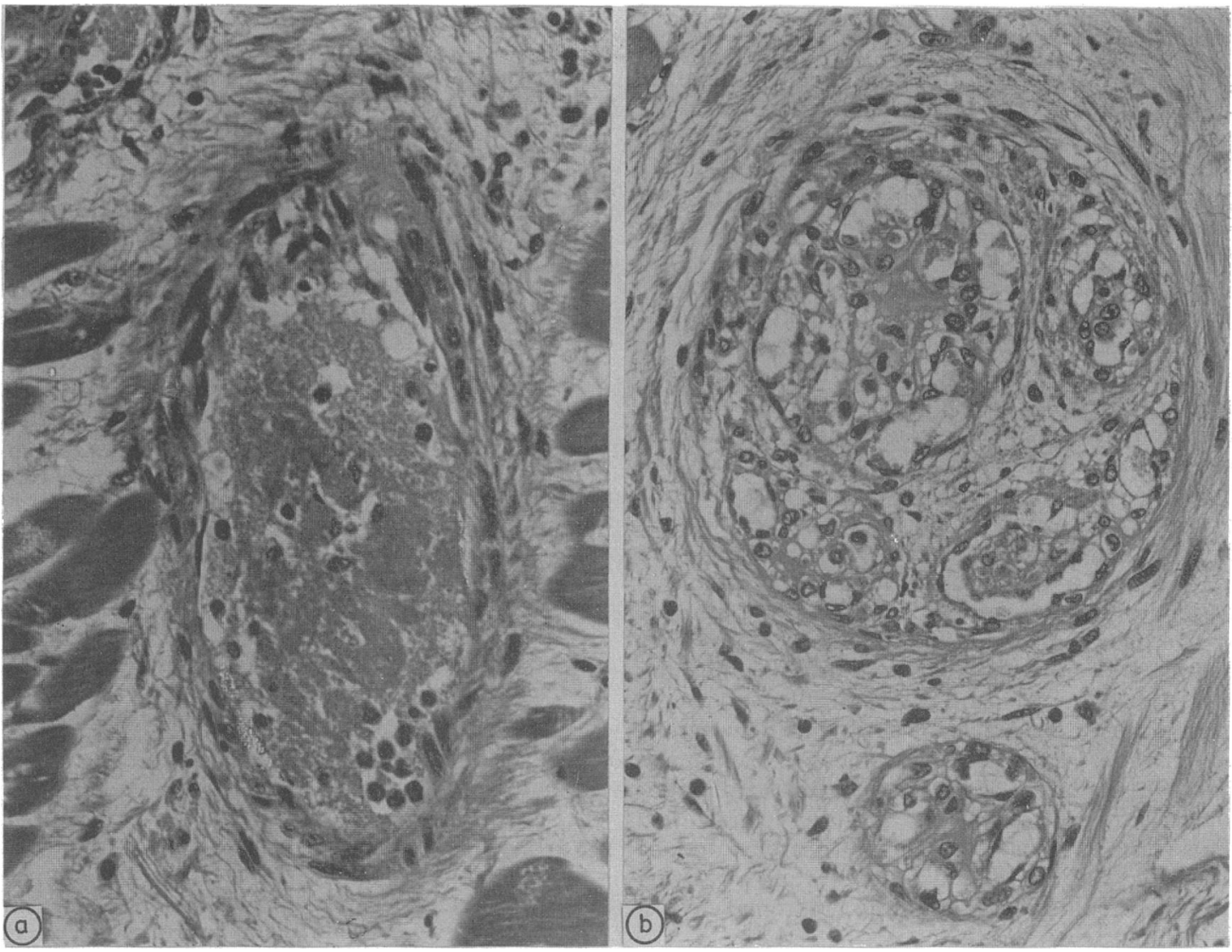

Fig 2 Two intramyocardial arterioles showing fresh platelet thrombus $(a)$ and extensive recanalisation of organised thrombus (b). Haematoxylin and eosin (original magnification $\times 370$ ).

recent while others showed evidence of organisation and recanalisation. Associated with these vascular occlusions were multiple microinfarcts, some of which were recent while others were organised fibrous scars. There were multiple microinfarcts with extensive small vessel occlusion and recanalisation in the brain and kidneys.

There was only slight atheroma of the aorta but there were several intimal plaques measuring up to $5 \mathrm{~cm}$ in diameter in the ascending aorta and arch. Histologically these showed fibrous intimal thickening with overlying platelet thrombus, which in places was being incorporated into the intima. Both lungs showed severe pulmonary oedema and there were bilateral adrenal haemorrhages that were thought to be an agonal event, possibly related to anticoagulation. Death was attributed to cardiac failure secondary to diffuse ischaemic myocardial damage.

\section{Discussion}

This patient had a history of myocardial and cerebral infarction, hypertension, epilepsy, and renal impairment. He presented with transient ischaemic attacks, aortic regurgitation, and haematological markers of a systemic illness. The clinical and laboratory findings did not support a diagnosis of systemic lupus erythematosus, whereas the features were characteristic of the anticardiolipin syndrome. ${ }^{1}$

The syndrome is characterised by thrombosis, thrombocytopenia, and recurrent abortion; but livedo reticularis, epilepsy, and both systemic and pulmonary hypertension are associated features. Renal disease when present is usually vascular in origin.

Two previous case reports in the British Heart Journal have described the thrombotic complications 
of phospholipid antibodies in patients with systemic lupus erythematosus. ${ }^{89}$ But while systemic lupus erythematosus and the anticardiolipin syndrome are closely related conditions, which may coexist in the same patient, each may also occur in isolation and the differing clinical and immunological features justify their distinction. ${ }^{2}$ This is illustrated by the current case where neither antinuclear factor nor DNA antibodies were detected.

An association between the anticardiolipin syndrome and both aortic and mitral regurgitation is now recognised. ${ }^{10}$ The heart is often affected in classic systemic lupus erythematosus ${ }^{11}$ but a recent echocardiographic series suggests that endocarditis, valve thickening, and unexplained impairment of left ventricular function occur almost exclusively in those who also have cardiolipin antibodies. ${ }^{12}$ In the present case, aortic valve histology showed features of a post-inflammatory valulitis; these changes are non-specific and their association with cardiolipin antibodies remains speculative.

The most important finding at necropsy was widespread microvascular thrombosis affecting myocardial, cerebral, and renal arterioles and resulting in diffuse ischaemic damage. We are not aware of any previous reports of such extensive thrombus of small vessels in the absence of clinical or immunological features of systemic lupus erythematosus. This case extends the range of cardiac lesions associated with cardiolipin antibodies and highlights the typical clinical features of the syndrome.

We thank Professor J R Hampton for permission to report this case and for advice with the preparation of the paper.

\section{References}

1 Hughes GRV, Harris EN, Gharavi AE. The anticardiolipin syndrome. J Rheumatol 1986;13:486-9.

2 Hughes GRV. Connective tissue diseases and the skin. Clin Exp Dermatol 1984;9:535-44.

3 Alarcon-Segovia D. Pathogenetic potential of antiphospholipid antibodies. J Rheumatol 1988;15:890-3.

4 Hamsten A, Norberg R, Bjorkholm M, De Faire U, Holm G. Antibodies to cardiolipin in young survivors of myocardial infarction: an association with recurrent cardiovascular events. Lancet 1986;i:113-6.

5 Morton KE, Gavaghan TP, Krilis SA, et al. Coronary artery bypass graft failure-an autoimmune phenomenon? Lancet 1986;ii:1353-7.

6 Loizou S, McRea JD, Rudge AC, Reynolds R, Boyle CC, Harris EN. Measurement of anticardiolipin antibodies by enzyme-linked immunosorbent assay (ELISA): standardisation and quantification of results. Clin Exp Immunol 1985;62:738-45.

7 Harris EN, Gharavi AE, Patel SP, Hughes GRV. Evaluation of the anticardiolipin antibody test: report of an international workshop held 4 April 1986. Clin Exp Immunol 1987;68:215-22.

8 Asherson RA, Mackay IR, Harris EN. Myocardial infarction in a young man with systemic lupus erythematosis, deep venous thrombosis, and antibodies to phospholipid. Br Heart J 1986;56:190-3.

9 Coppock MA, Safford RE, Danielson GK. Intracardiac thrombosis, phospholipid antibodies, and two-chambered right ventricle. Br Heart J 1988;60:455-8.

10 Asherson RA, Harris EN. Anticardiolipin antibodiesclinical associations. Postgrad Med J 1986;62:1081-7.

11 Ansari A, Larson PH, Bates HD. Cardiovascular manifestations of systemic lupus erythematosis: current perspective. Prog Cardiovasc Dis 1985;27:421-34.

12 Gomez P, Joshi J, Nihoyannopoulos P, Oakley CM. Association between cardiac abnormalities and raised anticardiolipin antibodies in systemic lupus erythematosis. Postgrad Med J 1988;64:723. 